\title{
Theodore H. Bullock (1915-2005)
}

\author{
Trailblazer in neurobiology.
}

Last summer, Ted Bullock and I walked under the wooden arcade covered by bougainvillea vines at Casa de Mańana, the retirement community in La Jolla, southern California, where he lived with his wife. All of a sudden, Ted stopped and pointed to the rich pattern of light and shade on the ground from the sun penetrating the plants. "Have you noticed that the size of the light points enclosed by the shadows are never smaller than a certain minimum size?" he said, and expounded the physical reasons he thought might cause this "quantum" phenomenon.

For Ted Bullock, who died in the night of 19-20 December 2005, no problem was too trivial to be examined, no question too simple to be thought about. This neverending curiosity was key to his success as one of the greatest neurobiologists of the twentieth century. Like no one before him, he pioneered a reductionist approach based on careful observations of a large variety of animal species under natural conditions to explore how nervous systems work, how they control behaviour, and how they developed during evolution.

Theodore Holmes Bullock was born to American Presbyterian missionaries in Nanking, China, in 1915. During his first 13 years, immersion in the Chinese culture, with its atmosphere of mutual respect, laid the foundation for his lifelong cosmopolitan outlook. He considered himself, " a citizen of the world first, of the United States second". After earning his $\mathrm{PhD}$ in zoology from the University of California at Berkeley in 1940, he spent four years at Yale University in New Haven, Connecticut, with summers at the Marine Biology Laboratory at Woods Hole, Massachusetts.

There, the ample opportunity to work on a large variety of organisms had a major influence on the development of Bullock's interests in comparative physiology. $\mathrm{He}$ continually searched for simple systems with which to explore the multitude of neural mechanisms that work together to produce an output, both at the physiological and the behavioural level. He argued that examination of the different mechanisms used by various organisms is as important as the search for commonalities in understanding how brains work. As a consequence, he studied an enormous number of different taxa over his lifetime, including cnidarians, crustaceans, fish, amphibians and reptiles.

His research life entered a decisive stage when he was appointed to the zoology faculty of the University of California at Los Angeles in 1946. Twenty years later, he moved to the University of California at San Diego, where he headed the Neurobiology Unit of the Scripps Institution of Oceanography and became a major force behind the creation of the world's first department of neuroscience.

One of the research themes to which Bullock returned time and again, was the role of direct current and low-frequency electric fields in intercellular communication in the nervous system. In the early 1960 s, the dominant view of neuronal communication was that it takes place only through action potentials, with chemical synapses acting as switches to regulate the flow of information through neural circuits. Bullock, however, showed that neurons can also communicate through non-synaptic interactions, and without such impulses. Using the cardiac ganglion of lobsters as a particularly favourable model system, he demonstrated that graded potentials spread electrically from one neuron to another through proposed low-resistance cytoplasmic bridges. Today we know that this type of electrical interaction is mediated by gap junctions electrical synapses that couple groups of cells into functional units.

As an extension of this work, Bullock maintained a lifelong interest in field potentials resulting from the summated electrical activity of millions of brain cells. He argued that present approaches to analyse these electric activities are insufficient to extract all of the information possibly used for signalling within the brain. Furthermore, he demonstrated that certain patterns of field potentials underlying cognitive processes can be recorded not only from higher brain centres in taxonomically higher vertebrates, but also from sites involved in low-level sensory processing (for example, the retina) and in lower vertebrates, such as rays and turtles. On the basis of Bullock's research, this comparative approach has proven to be a powerful tool for uncovering principles of the evolution of cognition.

Bullock's other scientific contributions include the discovery of two new senses in animals. In a series of papers in the 1950 s, he and his associates showed that the facial pit of pit vipers, located midway between the nostril and eye on either side of the head, acts as a thermal sensor. The snakes use receptors in the facial pit to detect temperature changes caused by prey animals in the vicinity. A second landmark discovery

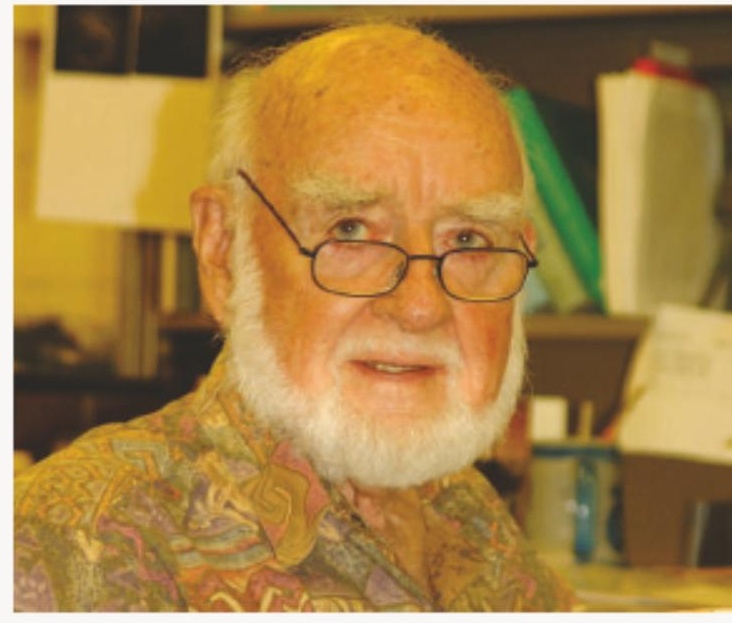

came in the early 1960 s, when he and his colleagues found a novel class of sensory organ in the skin of certain fish. Using a specialized organ, these fish produce weakly of electric discharges that aid orientation and communication with members of their own species. The receptor cells of the electric sense organs respond to electric fields, even of extremely low intensities, and are tuned optimally to detect the fish's own discharges and those of neighbouring electric fish.

A researcher who maintained the highest standards, Ted remained enormously productive until his death. He was an inspiring teacher who encouraged broad education and independence. Over his lifetime, he attracted a tremendous number of graduate students, postdocs and visiting investigators from all over the world, helping many of them to enter promising research areas, without necessarily pursuing the field himself. Above all, his attitude towards people was clearly that of a humanist. He was dedicated to his wife of 68 years, Martha, and their two children. He always had time for other people and, when asked, gave advice - not by dictating what to do, but by presenting a well-balanced analysis.

The volume of his correspondence with friends, students and colleagues all over the world was immense and hardly decreased with age - as the photo above from last year shows, he remained youthful and vigorous even at 90. His last e-mail to me was sent just a few hours before his death, with detailed suggestions on a manuscript. $\mathrm{He}$, who considered it a duty and a pleasure to help others, finished his e-mail " thanks for the privilege. It was a privilege to be among those with whom he shared his wisdom, enthusiasm and love for science, nature and people.

Günther K. H. Zupanc

Günther K.H. Zupanc is at the School of Engineering and Science, International University Bremen, PO Box 750561 , D-28725 Bremen, Germany. e-mail:g.zupanc@iu-bremen.de 